075.

\section{A Lesson from the Rwandan Tragedy: The Need for Integrated Medical Emergency Relief Programs}

Andre J. Neusy, $M D$

New York University Medical Center, New York, NY, USA

In July 1994, more than one million Rwandan refugees fled the atrocities of a civil war, crossed the Zairian border, and flooded the resort town of Goma, where they were met by a major cholera epidemic. The refugees were quickly moved by the Zairian authorities to unsuitable areas with no water source in a region covered by lava outflow, thus prohibiting the digging of graves and latrines. Thousands of uncollected bodies were lying in the Kibumba camp with a refugee population estimated at 350,000 people.

This presentation will describe the various phases of a joint relief effort sponsored by the International Rescue Committee in collaboration with the American Jewish Joint Distribution Committee. We will discuss the lessons learned from establishing the first line medical aid, the availability of medical back-up support, the build-up of a sanitation program, the utilization of human resources in the refugee community, and the creation of health posts and health centers. Finally, a case will be made for better coordination between the various relief agencies and for the creation of integrated multidisciplinary emergency relief modules with rapid intervention capability.

\section{0.}

\section{Major Determinants Influencing the Size and Components of a Medical Delegation to a Mass-Casualty Region}

\section{Lt.Col. J. Peleg}

IDF Medical Corps, Eldad A. Burn Unit Hadassah University Hospital, Jerusalem, Israel

Various countries and nongovernmental organizations offer medical aid in reaction to various mass-casualty disasters. Since disasters vary in magnitude, extent, location, and nature, so is the type and extent of medical care required very heterogeneous. Various aspects of needs assessments, manpower resources, equipment available, transportation capacities, volume and the nature of the medical delegation offered are inter-related, and ultimately will influence the construct of the medical help provided.

The aim of this paper is to analyze the various components of such decision-making: time, date, resources, definition of aim and targets. Through this analysis, we will try to assist those who will have to plan a medical delegation for disbursement to a disaster area. The dilemma between thorough screening, data collection, needs assessment, and prompt, actual medical help is highlighted.

The major role of any coordinating organization in such conditions, and the crucial aspect of communication between the coordinating organization and the various governmental and volunteer organizations will be discussed with special refer- ence to the effects of these relations on the planning aspects of the medical missions.

130.

\section{Disaster Management Training for Hospital Staff}

Dr. V. Anantharaman

Accident and Emergency Department, Singapore General Hospital, Singapore

Disasters demand extremely rapid mobilization and reorganization of personnel and logistics in a hospital. Senior hospital managers often presume that their innate management abilities will see them through disasters. Frequent disaster exercises are not welcomed and often are taken lightly by hospital staff and management. Hospitals, therefore, continue to experience chaos and confusion especially during the first few hours of a disaster management effort.

Singapore General Hospital recently embarked on a Disaster Medicine Training Program. The first such course in disaster medicine involved a series of lectures, including some on the organization of hospitals and blood, forensic, and psychological support. This was followed by a whole-day disaster simulation exercise involving management of three hospitals.

Disaster medicine simulation training packages for hospitals can be built-up for the following areas:

1) Training in hospital's mobilization and recall system;

2) Training of emergency department senior and junior management in departmental organization, patient flow, and intradepartmental coordination during disasters;

3) Training of the operations theatre senior staff in organizing theatres, theater teams, mobilization of various grades of staff and types of equipment, and interacting with other areas, e.g., intensive care, emergency, disaster ward(s), and a hospital command post;

4) Training of intensive care staff for coping with disasters;

5) Training of operations of disaster wards;

6) Training of hospital senior management in the control and coordination of key hospital areas during disasters.

\section{9.}

\section{The Emergency Physician: Let's Talk About the Best Formative Iter}

Maurizio Barbero, MD, Francesco Bermano, Salvatore Esposito, Maria Gazia Guiddo, Fiorella Robba

Emergency Center, St. Paul Hospital, Savona, Italia

The sanitary emergency always has represented a weak point in the organizational structure of the sanitary system for a couple of reasons. The first is represented by the aspects typically connected with the timeliness of the intervention in a condition of critical pathology, and the second regards the emotional impact produced in the patient. These are the reasons that these particular physicians need a qualified, formative system 